\title{
Factors Affecting the Effectiveness of the Implementation of a Modern System of Financial Management and Control in Albania
}

\author{
Ariana Konomi \\ "Eqrem Cabej" University, Gjirokastra, Albania \\ arianakonomi@yahoo.com
}

Abstract

\begin{abstract}
One of the three pillars of public internal financial control is financial management and control. Through this work, we aim to address the factors which influence the effectiveness of the implementation of a modern system of financial management and control in public sector entities. "The model of Public Internal Financial Control is welcomed and widely implemented in many countries, within and out the European Union. It has a track record of success and I strongly recommend that countries should follow the exciting journey toward the world art of internal control system ${ }^{1 "}$. This system means: assignment of authority and responsibility; empowerment and accountability; and appropriate reporting lines, resulting in improved governance of the organization.Based on data on self-evaluation questionnaires (COSO model) designed by CHU / FMC for public units of the general governance, about the opinions on each component of the system and on the first results obtained from questionnaires sent in some local government units it will be analyzed, that the effectiveness of the modern system of FMC in Albania depends on: The level of knowledge, in the Albanian context, of concepts and principles of FMC; Simultaneous functioning of its five components for each category of principles; Undertaking the appropriate management actions.
\end{abstract}

Keywords: FMC-system, managerial responsibility, control activities, risk management

1. The right conception, the development of legal and organizational framework of the public internal financial control

To implement the Public Internal Financial Control (PIFC), it should be considered the following stages: the conceptualization/understanding, the development of organizational framework, the development of the legal framework and the creation of a staff development policy. In practice, these stages are interrelated and often experience shows that all phases begin immediately after being agreed with the concept ${ }^{2}$.

Correct Understanding, based on the international standards, allows the analysis of gaps and needs in the current systems of internal control. Consequently, the recommendations given, on which will be implemented the next actions, will be effective. The right conception is also reflected in the manner of drafting the Policy Papers, where it should be presented, ideally, the action plan, specifying the important decisions that have been taken or will be taken, as well as the activities that are planned to be executed. It is suggested that the Policy Papers should be designed and structured in a certain and logical way in terms of content and presentation.

Policy Papers on Public Internal Financial Control (PIFC) in Albania, approved by the Council of Ministers in June 2005, revised in 2009, has determined the current system of PIFC and the control environment in Albania ${ }^{3}$. Policy papers describe the current state of the PIFC system, the controlling environment, as well as policies and plans for updating and improving

\footnotetext{
1" Welcome to the world of PIFC" Luis ROMERO REQUENA Director General DG Budget

2 Ministry of Finance " Annual Report on the Functioning of Financial Management Systems and Control and Functioning of Internal Audit in the General Government entities for the period 1 January - 31 December, 2013," May 2014

${ }^{3}$ Republic Of Albania Council Of Ministers Decision No. 640 Dated 11/6 /2009" For The Approval Of Policy papers Of Public Internal Financial Control And Action Plan, 2009-2014
} 
internal control, the main directions and obligations of public sector entities, in order to enable them to provide reasonable guarantees that public resources are managed with efficiency, effectiveness and economy 1 .

To fully implement PIFC and the purpose of the task of methodologies and standards harmonization at all levels of government, it is required a long period of time. "The implementation of PIFC should be seen as a long-term process that requires the commitment of all stakeholders. Experience has shown that the introduction of new policies and laws on this subject has not previously been based on the understanding and approval of all ordinary stakeholders, leading to a resistance, which could jeopardize the entire project of change".2 It is necessary to establish a Central Harmonization Unit authorized to manage the development and improvement of PIFC of a country.

The $\mathrm{CHU}$ with a professional staff is perceived as a necessary condition to provide a thorough understanding of the requirements of PIFC by managers in all spending units and to provide appropriate support guidelines. This $\mathrm{CHU}$ normally is established in the Ministry of Finance and reports directly to the Minister.

"The experience has shown that a strong commitment by the central authority is the most important condition for the management of the change of the PIFC's project. In almost all cases the central authority was the Ministry of Finance (MoF). This is logical because the issue of selecting adequate internal control of the national budget is at the core of a sound financial management". 3

"In the responsible ministry for finance, in Albania, functions the General Directorate of Regulatory and Control which has two central harmonization units on its dependance, the $\mathrm{CHU}$ for the financial management and control ${ }^{4}$, and the $\mathrm{CHU}$ for the internal audit, responsible for the internal audit system, necessary for the proper management of PIFC implementation across all the public sector. These services of audit should report to the highest level of management: the minister in government ministries and the director/head of public agencies. Lower levels of government (regions, municipalities and communes) should "reflect" the principles of control and establishment of PIFC, taking into consideration the economy and efficiency.

PIFC should be based on law. Based on the conclusions and recommendations of the Policy Papers, the next stage will be to draft a new comprehensive legislation, covering CHU / IA and CHU / FMC. International best practices have shown that it is necessary first, the establishment of a law that would serve as a conceptual framework covering the main principles of PIFC. Later, secondary legislation should be drafted in accordance with the definitions in that main frame and, when it is necessary to work on regulations or guidelines that can be updated without going through the parliamentary procedures of approval. In Albania in 2010 it was approved the law on financial management and internal control system and its implementation manual. Policies regarding public internal financial control aim to establish a full framework, legal and procedural, in the framework of the reform and development of public finances.asoje 4

"The public finance sector will be professionally oriented towards the mobilization and use with efficiency, transparency and integrity of the financial resources of the country, in accordance with the policy and priorities of the Government's Programme and the National Strategy for Development and Integration"5. The introduction of financial management and control is much more than a technical reform. Setting the new regime of financial control, the public internal financial control (PIFC), includes international standards and the best practices of the EU and aims to ensure optimal approach for the reformation of the traditional national control systems. The presentation and development of PIFC is filled with challenges such as "managerial accountability" and "internal audit functionally independent and decentralized". Managerial accountability has its roots in the concept of effective management

Effective management and managerial accountability require the support of an effective system of financial management and control, because management does not happen in a financial vacuum, the entire management activity is subject to the constraint/financial obligations. Since the pressure on public resources is always to deliver more with the same (or less)

\footnotetext{
${ }^{1}$ It was drafted on the basis of independent evaluations by the Directorate-General of the Budget, (European Commission, Brussels), and SIGMA, and it is also considered the analysis of gaps conducted within the twinning project "Development of Public Internal Financial Control

2 EUROPEAN COMMISSION: Welcome to the world of the Public Internal Financial Control (PIFC)

${ }^{3}$ EUROPEAN COMMISSION Welcome to the world of the Public Internal Financial Control(PIFC)

${ }^{4} \mathrm{CHU} / \mathrm{FMC}$ has the responsibility for developing FMC standards in the public sector

${ }^{5}$ Public finanvcave Strategy 2007-2013
} 
sources, it should be taken into consideration efficiency and effectiveness. FMC is designed to provide this essential financial support for managers ${ }^{1}$. The proper implementation of the new legal framework and efforts by all stakeholders can lead to achieving the goal-the creation of a modern, reliable and functional public internal financial control system. PIFC is not focused on budgeting or accounting techniques (although internal control can also recommend improvements in these systems), nor does it include inspection tasks such as investigation and prosecution of individual cases of fraud or serious irregularities.

Public internal control is preventive on its nature and aims to ensure that adequate systems are in place to prevent as much as possible the phenomena of corruption and fraud Public internal control is itself subject to external evaluation by the Supreme Audit Institution². This model of Public Internal Financial Control is welcomed and widely implemented in many countries, including outside the EU. "It has a history of success and I strongly recommend the countries to enter in the exciting journey toward the world of art of internal control system"- said Luis Romero Requena, Director-General of the budget of European Delegation. In Albania, the Ministry of Finance is implementing the 5-year plan for a modern system of FMC and currently is integrating long-term objectives of the implementation of FMC in public finance Strategy 20142020.

\section{Standard requirements for financial management and control}

Financial Management and Control is a comprehensive process of the unit activities, and is developed by both the managerial level, and the staff of the institutions ${ }^{3}$. This process has an objective to provide reasonable assurance that the objectives of the organization are achieved through:

1. Economically, effective and efficient activities;

2. Compliance with the legislation and internal acts and contracts;

3. The financial and operational information which are reliable and complete;

4. The protection of information and assets.

Financial Management and Control in the public sector is achieved through:

1. The creation of an efficient and effective control environment;

2. Effective risk management;

3. The proper implementation of control activities;

4. Management of communication and information;

5. Monitoring the control activities of the public sector entity.

The factors that should exist to support a sound FMC system are:

1. The objectives of the policy should determine the operational activity.

2. Managerial structures should be designed to determine the objectives of policy (ie. to be clear who are the leaders, the resources made available to them, their responsibilities, and the areas of competence and reporting).

3. The operational activity should be evaluated regularly by managers to ensure that it meets the needs of users in accordance with policy objectives and that these activities are based on principles of economy, efficiency and effectiveness.

\footnotetext{
1Ministry of Finance "Annual Report on the Functioning of the Public Internal Financial Control in the General Government Units year 2013" May 2014

2 EUROPEAN COMMISSION Welcome to the world of the Public Internal Financial Control ( PIFC )

${ }^{3}$ Law on "Financial Management and Control" No. 10296 in July 2010 and the Manual for FMC
} 
4. Only those assets that are necessary to achieve the policy objective or activity should be retained and the rest to be donated/sold, given for use or disposed of.

5. Managers should have access to specific information (financial and operational) needed to ensure that objectives are being achieved in line with the principles of economy, efficiency and effectiveness and in accordance with the plans and programs.

6. Managers should take full responsibility for specifying the internal control system and the effectiveness of these systems.

7. Managers should consider the risks for planning the measures for the realization of policy objectives.

\section{The performance of FMC implementation in Albania- Results and analysis.}

Management theory researchers have considered that the definition of the OECD organization (Organisation for Economic Cooperation and Development) on 1999 about governance is useful, it is seen as "a system in which activities are directed and controlled", but the transition towards "good governance" reflects new substantial effects. Thus, "good governance" implies the accountability relationships between the main actors of the system of public internal financial control within which operates: the Board of Directors, internal auditors, managers, executives, external auditors. Referring to the effects of the financial crisis and the massive spread of innovations and new technologies, it is necessary that the system of public internal financial control to be improved by reviewing the components and its constituent elements. This should be done in order to get revised, improved and developed, and a greater guarantee to be achieved, and also the risk should minimized, which is constantly present and follows us at every turn.

The implementation process will require ${ }^{1}$ : (i) changes in management structures within the organization, including the revision of the status of executive officers; (ii) the definition of the roles and relationships between leading financial management officers; (iii) necessary considerable training, at least for the enforcement officers who are expected in the future to provide information to the managers, which they need to ensure that they are using public resources efficiently and effectively.

The Directorate of Harmonization of Financial Management at the Ministry of Finance, in collaboration with consultants of the PIFC Project funded by the EU, has prepared based on the COSO model, questionnaires for assessing/monitoring the quality of financial management systems in public institutions as well as regarding the applicability of the instructions of the Ministry of Finance.

The purpose of the questionnaire is to address the level of satisfaction about the main demands in the internal control framework regarding the five components of FMC-control environment, risk management, control activities, information, and communication and monitoring. This questionnaire helps to identify those aspects of internal control, where further awareness is needed and where the needs for training should be addressed.

As a source of information for the analysis of the condition of components of financial management and control were used the self-assessment questionnaires on the components of FMC, which the Department of Harmonization of Financial Management has developed based on the COSO model. The results are published in the annual report of 2014 for the past three years. The data reported by the internal audit structures of the local government according to the format approved by the Minister of Finance, have served for the analysis. As a source of information for the functioning of financial management and control have served data obtained regarding the completion of the declaration and the annual report for the quality of internal control in the Central Government Unit in the whole country ${ }^{2}$, and the answers received from the meetings arranged by myself in oder to monitor closely the responses to these questionnaires and those designed by myself based on the same model. From questionnaires collected by myself from some CGU 's, in the major part of the

\footnotetext{
${ }^{1}$ Annual Report on the Functioning of Financial Management Systems and Control and Internal Audit Function in the General Government entities for the Period 1st/January-31st/December, 2012; consolidated report of SAI on the FMC system in 2012 pg 9

2 Reported by MF
} 
district of Gjirokastra, and the meetings with the implementing officer, internal audit and managers of these units deficiencies and gaps has been noticed which are identified and presented also by the Ministry of Finance.

Regarding the internal control environment, the questionnaire consists of a certain number of questions regarding the integrity, ethical values and the professionalism of the employees of the organization; the philosophy and working style of the management; the way the manager distributes tasks and assigns responsibilities or the way he organizes and progresses the employees in the institution; organizational structure; setting objectives and policies, etc. It is notable that $25 \%$ of the general government units, mainly local does not meet the requirements of the Law 9936 "On the budget system management in the Republic of Albania" related to the mission statement drafting in public entities, and although around $19 \%$ of them have developed the mission and strategies, they have not developed an action plan with deadlines and resposnible persons.

The trend of negative responses, in terms of percentage, has been the same for the last three years 2012-20141. Moreover, in a significant portion, around $15 \%$, the staff was not familiar with the mission and strategies, as they were distributed only in the top level of the entity. The authorizing officers are generally assigned according to the law. There is a growing trend of the assignment in accordance with the legal requirements of the Implementation officers of public entities. Only $28.6 \%$ of the public entities do not meet the criteria of education and the direct dependence of the executive officers on the authorizing officer. They are not high-level managers, but chiefs of the finance sector and are not part of GMS's, in around 90 entities of the general government. From the responses it results that the Strategic Management Groups are established on $79 \%$ of the CGU, in accordance with the legal requirements, although they operate mainly during the planning process ${ }^{2}$. Particularly in the local entities they are not effective in terms of the operation process.

From questionnaire responses, as concern to the personal and professional ethics, and by monitoring via meetings in the country, concerning the questions addressed in this section, it was observed that the answers were positive regarding only the implementation of the legal framework for ethics. This does not turns out as concern to the specific activities ie, from the verification during the meetings arranged, there were no written procedures for ethical dilemmas. Meanwhile, according to information received from MoF it is accepted that there exist such procedures in about $70 \%$ of the CGU, mainly central institutions, which have included rules of ethics in internal regulations.

The dominant part of public entities officers demonstrate the proper functioning of the reporting ways, regular arrangements of meetings on the managerial level of the entity to discuss key issues of the management of the entity.

Regarding the management style in some local public entities in the district of Gjirokastra, the way the meetings were organized was described in the internal regulations of the institutions. Regarding the communication with the internal audit, the responses in these entities show that the interaction between the Head of the institutions and the internal audit results effective. But by concrete monitoring, it was found that in some enitities there was not any internal audit planned and approved within the structure. In the enitities that it was applied, it was proved that it is not yet properly understood the role of the IA (Internal audit) as an advisor of management for the improvement of the IC system in the respective entity. One of the essential consisting elements of the management style is the delegation of tasks. Currently by monitoring the LGUs for $\mathrm{AO}$, it is observed lack of desire for delegation in the levels of dependency as well as defficimcies towards this direction, especially in the non-existence of written procedures for the delegation way and the description of the competences which could be delegated.

Regarding the answers about risk management in these local enitities, a negative answer is observed from the questionnaires regarding all questions of this section, but the coordinator of risk was defined, which according to the law is the authorizing officer. The positive answers for this component did not agree with reality. By monitoring the process it was found that the role of the coordinator of risk is not understood, there are no risk management procedures, drafted strategies of risks that hinder the accomplishment of objectives.

Control activities, being one of the five components of FMC, aims to reduce the risks to achieve the objectives of the organization and to promote the implementation of the decisions of the office-holder. Local public entities claim to have met the minimum legal requirements and have implemented appropriate controls in the following areas: the existence of

\footnotetext{
${ }^{1}$ Report of Ministry of Finance for PIFC for 2014 pg.12

2 Report of ministry of finance for PIFC for 2014 pg.15
} 
internal rules/guidelines to describe the main financial and operational processes, segregation of duties, delegation of tasks and responsibilities. In public entities the trend of answers in percentages for the last three years has been positive. In this section the answers are positive and evaluated with maximum points, but in fact when it comes to delegation of tasks, it is applied only the delegation for the cases of absence, through the authorizations based on the protocol.

Regarding the separation of duties it can be said that in most public entities (in all central enitites and partially to the local ones) exist the job descriptions. They are included in the internal regulations or, in the job contracts. Any continuous changes in the structure and in the departments' formatting require also continuous revision of internal regulations of the institutions. From the monitoring it was found that in some ministries there were not reviewed the internal regulations but steps have been taken towards this process, whereas in the dependent enitities there were not done any revisions of regulations since 2007. From the answers given and monitoring it is noted that in practice there is a missunderstanding of the necessity of the existence of descriptions of business processes. Very often the description of the working process is confounded with the description of job position.

The responses were positive regarding the protection of assets from misuse. We note that the concern of managers is expressed only regarding the fact that the assets exist physically and protected by the entity. The developement of the IT systems to improve the preventive control activities was negatively assessed in the questionnaires. Institutions have presented as problematic the transfer and overloading of the executive officer with powers, and lack of powers of the subordinate structures for evaluation and disposal of assets.

The fourth group of the IC components is related to the information and communication issues. According to the responses from the questionnaire provided for the Ministry of Finance, it has a positive assessment for the component of this system. It would have not been received the same response from the LGUs in Gjirokastra on specific issues, such as making available the information needed to perform the tasks, as well as on the existing routes of communication for irregularities. The information systems are evaluated sufficiently for these specific issues, by not giving managers the opportunity to assess the fulfilment or not of the objectives of the performance standards.

Despite the responses received, the Ministry of Finance by monitoring the process in the country has reached the conclusion that it has not yet been developed a system of communication and suitable information. A correct judgment on the quality of the reports provided by the managers can not be made. Financial reporting is usually considered as a matter of the authorizing officer $(\mathrm{AO})$ and implementing officer $(\mathrm{IO})$ and it is less done by the line managers. There is also a lack of understanding on how to use financial information to improve efficiency and effectiveness, and this is due to the focusing on the traditional control. Consequently, it is hampered the daily work and managerial decision.

Monitoring is a set of processes to review the activity of the institution, which aims to provide reasonable assurance that the control activities function according to the purpose for which they were created and remain efficient over time. From the monitoring, it is noticed that the kind of reporting or monitoring should be improved and there should not only be a focusing on the traditional financial reporting but also on performance.

The effective functioning of Financial Management and Control also requires a strong accounting service in the entities of central and local government. Accounting and reporting systems are among the mechanisms of control that show significantly the functioning of this system, especially the financial operations.

\section{Transparency and accountability in the public sector- an important factor in the effective implementation of the financial management and control system}

\subsection{The standard set by the FMC system for accounting and budget}

In addition to the meet the requirements of financial management and control each financial accounting system of the entity should ensure that:

- All transactions are recorded in accordance with accounting principles; 
- The organization of accounting documents allows the preparation of the necessary reports for external and internal information users (ie., auditor);

- The financial reports show the true and fair financial condition of the entity, the positive results/deficit for the period accounted for, as well as the cash flow.

- $\quad$ Each unit must implement appropriate procedures of FMC to ensure:

- Registration of all transactions on time;

- Proper classification of transactions and activities as required;

- The presence of the necessary authorizations;

- $\quad$ Full documentation, designed according to the requirements, and its storage;

- The availability of information.

- The entity must ensure the preservation of the following information, related to the transactions:

- Documents that serve as the basis for the transaction, including all additional documents (such as copies of invoices, procurement requirements, etc);

- Documents that report the specifics of audits performed (ie. lists of verifiability, audit reports referring to transactions, etc.).

- Assets management is a fundamental part of financial management, so it is one of the responsibilities of the authorizing officers of the public sector entities. Each unit should establish procedures for the acceptance, effective and efficient use of assets, storage, movement and disposal of assets under their control. For this reason everyone should understand better:

- The content of the actual base of assets;

- That the assets should provide efficient and cost effective services, and;

- What does this mean for purchasing, storing and their disposal?

It is a good business practice for each entity to draft, maintain and update a register of all assets that owns and uses. This register will be useful for the preparation of its accounts. It is also a good practice for the verification of the status of the actual assets of the entity and to plan changes. The register of assets of an entity should include tangible and intangible assets, and specify the assets owned by the entity and those found under his legal control. Each entity must establish a reasonable threshold to assess the assets.

When drafting the register of assets, special attention should be paid to two types of assets. Attractive assets, such as works of art and other items that may be at risk of getting stolen must be paid special attention. These assets may be included even if they are below the threshold of assessment, as well as investments in the form of shares and bonds in trading companies. These should be checked at least once a year.

\subsection{Institutional arrangements and policies regarding accounting and reporting function in the public sector}

The FMC system implies the assignment of authority and responsibility; empowerment and accountability; and appropriate reporting lines, resulting in the improvement of the organization governance. The challenges faced by Albania to develop its PFM systems (public financial management) in the medium term are: (i) to establish a single framework of national strategy through the implementation of the Integrated Planning System that takes into account the constraints of public resources and strengthens the policy of formulation and coordination; (ii) to provide a stronger political commitment to the development of medium time term budget program (MBP) in order to develop a budget process driven mostly by economic policies; (iii) to improve the efficiency and accountability of the budget implementation process, among them: treasury management and cash systems as well as public procurement operations; (iv) to address the critical situation of the staff and the constrained capacities in the PFM and line ministries which continue to influence all the elements of the PFM 
system; and (v) the establishment of a larger external responsibility to the parliament and civil society for planning and budget systems ${ }^{1}$.

The Board of the International Accounting Standards of the Public Sector (IASB) 'has promoted the need for increased transparency and accountability in the public sector, noting in particular the risk present caused by the lack of transparency and accountability for the efficiency of capital markets, global financial stability and long-term sustainability2.'

The Board of the International Accounting Standards (IASB) recognizes that, to improve financial management in the public sector, the governments need to make institutional arrangements, to implement the necessary institutional arrangements to support transparency and accountability, including: (i) the preparation and dissemination of financial reporting with high quality and on time; (ii) publication within six months from the end of the period of the financial statements which are independently audited; (iii) the preparation and publication of public sector budgets on incremental basis and on time; (iv) complete preparation, transparency, the publication of all financial reports and budget allocations in a sufficient amount, appropriate and before the elections; (v) Principles creaated, well-established, and publicly available for fiscal management and control, with full transparency (publication on time) to show that the principles are being followed ${ }^{3}$.

Traditionally, public administrations have set their own standards for accounting and financial reporting. To achieve the social and political goals, i.e. to achieve the management and control of public entities by the society, in the public sector, for the process of management, are used regulations which provide legal and administrative restrictions (such as decisions and instructions of the Council of Ministers). The latter and the features of the economic, social, legal and politic environment where the public sector acts, focus the public sector accounting on the control of the provision of financial resources, on the activity for the good administration and their use with responsibility in accordance with the laws and regulations in force.

As a result, while the fundamental principles of public sector accounting are the same as those in the private sector, the presentation of the statements and accounting aspects differ, especially the creation and use of financial resources. Two main legal and financial tools are used to achieve these goals, accounting and budget. Key concepts upon which are based the accounting and financial reporting in the public sector in Albania are accountability and coverage of the current expenditure from current income ${ }^{4}$. Policies regarding public accounting function aim to improve the public expenditure and manage the wealth and the increase of fiscal transparency, thus being consistent with the principles of financial management and control (FMC). This will be achieved through the preliminary control (ex ante) of the public accounting procedures and the reporting procedures. The main policies are:

The preparation and application of Accounting Standards and Reporting Formats for the execution of the budget, to be used by the Treasury structures and spending entities. Accounting standardization and reporting in the public sector is not only necessary, but also essential in order:

- To improve the quality of decision-making at all levels of government

- To enhance the effectiveness and efficiency of resources

- For the formalization of the economy and to better combat the phenomena of corruption, fraud, abuse, dirty money, etc.

- To improve the level of fiscal transparency with the public

- To get integrated and faced with the global economy

\footnotetext{
1 Report no. 36,453. Shqiperia- Restructuring Public Expenditure to Sustain Growth," A review on Public Expenditure and Institutional framework" Volume II: Main Report December, 2006. Unit of Poverty Reduction and Economic Management in Europe and Central Asia Region Document I of the World Bank

2 IFAC "The Importance of Accrual-based Financial Reporting In the Public Sector," April 2014

3IFAC (March 2012), "The public sector financial management and transparency. Accountability, use of IPSAS"

4 Public accounting, 2009, Irena Bogdani
} 
The acceleration of work for the formal adoption of GFSM 2001 for accounting, including the extraction of data arising with high frequency (monthly cash flow and quarterly data for the government operations), as well as quarterly data for the public non-financial debt'1.

In the context of developing and implementing IT infrastructure based on the Oracle program,

- It will be drafted a new law on "Accounting in the public sector" and the provision of national standards of public accounting based on international accounting standards in this sector, according to IPSAS.

- It will be designed and documented as soon as possible a national system of accounting for all the sub-sectors of government, based on the classification GFSM2001 (manual of fiscal statistics of the government). To meet the immediate reporting requirements in the context of accession in the EU, the government will begin early the preparation of financial reports following the principles and formats of the GFSM, SELL 2010².

The information system will cover most of the aspects of keeping budget and accounting: Preparation and maintenance of the budget, treasury, fixed assets, inventories, financial statements, procurement, the management of revenue and cash budgeting, accounting, financial reporting etc. Currently it is only implemented the module of revenues and, budgeted and finished expenses. Work is in process regarding the other modules. In view of the implementation of budgetary funds there also operates a Budget Institutional Classification, in which it is distinguished the entities involved in the management of costs and revenue budgeting.

The treasury system established in Albania in May 1993, manages the costs and budget revenues under this classification. It is based on obligations defined by the law of Budget system management in the Republic of Albania, which is based on the cash basis of accounting. Accounting from general government institutions in Albania is currently implemented on a cash basis, but with elements from asset administration, commitments, debtors and creditors. Financial reporting is directed towards the budgeting way and control of implementation of the state budget ${ }^{3}$.

The General government institutions, which use the modified accounting system on the basis of the rights and obligations assumed, at the end of each year produce a balance sheet that includes all the budgetary and non-budgetary operations, performance accounts (statements of the income and expenses of the current activity, expenditure statement of investment activity and the sources of its funding), a statement of cash flows and disclosures. Various financial statements issued by various entities are consolidated by a Director at the Ministry of Finance.

In these consolidated statements are include the financial statements issued by line ministries, local governments, health insurance fund and social insurance fund. The statements of state enterprises are consolidated under the net capital method ( $100 \%$ owned by the state). The treasury Department, as noted, uses the system of accounting cash basis, as an instrument to manage and keep under control the cash flows, so every year should be made a reconciliation between the records of the Directorate which consolidates the financial statements of budgetary units designed on the current modified basis, and the Financial Statements of cash Flows of the Treasury Department, which is always accompanied with problems and difficulties.

At the level of consolidation, are taken into account the rights and accrued liabilities, as well as the fact that accounting has begun to shift towards a system based on the modified accounting of the accrued rights and liabilities. In the budgetary regime, the costs ie, of raw materials and construction equipment, are recorded as capital expenditures, for the purpose of the budget, and then they are transferred in the long term assets to be amortized later. Since 2000, with the technical help of WB is supported the implementation of a project for a new integrated financial system, to maintain the budget and accounting in Albania.

This project aimed to create a complete and operational treasury system and to improve the formulation and implementation of the budget. The project currently is under implementation. Through this procejt, 36 structures of the Treasury Director of the district are equiped with computer tools (materials and software) suitable for data collection, management and share of

\footnotetext{
1 Public Finance Strategy 2007-2013, As a part of the integrated planning system in Albania, covers among others the field of financial management which includes: treasury function, public sector accounting, public internal financial control

2 The strategy of public finances 2014-2020

${ }^{3}$ The strategy of public finances $2014-2020$
} 
their accounting data. Via full implementation of this program it is expected to get enabled the preparation of financial statements for all the important reporting entities of public sector.

This will be achieved after the full implementation of the third phase of the project for the reformation of the Treasury System, when all the users of the system will be included in the network and when the system will function integrated with all its constituent elements. The main focus continues to remain the reporting of financial information with respect to such expenditures against the plan. According to the public finance strategy 2014-2020, the government will improve the procedures and the raporting patterns within the year, by combining the financial information from accounts with material information on activities and the results related to the planning and budgeting. In addition, the reporting system will be fully implemented in the information system, in the future, and not on paper, and will be accessible by all ministries 1 .

The legal infrastructure and regulations of Accounting and Financial Reporting in the Public Sector, the transition towards the international accounting standards in the public sector and the European standrads of public accounting, recognition, acquisition and their use by professionals of this sector, would simultaneously constitute a necessity and the most important challenge in this sector. Standardizing accounting and reporting in the public sector is a process that requires time and at the same time a continuous reformation of the policy, institutions, structures and professionals, but it is also one of the important factors for managers to have access to specific financial information necessary to ensure that the objectives are achieved in accordance with the principles of economy, efficiency and effectiveness and in accordance with the plans and programs.

\section{Conclusions and recommendations}

Albania will continue to develop the Public Internal Financial Control in line with the EU requirements and the international standards of FMC and Internal Audit. Implementation of all these standards by all public administration in Albania is a necessary condition for the recognition and observance of all legal norms and requirements of the EU, for candidate countries, which are about to integrate in the EU.

By monitoring the answers to the questionnaires it is noted that there is a formalization of this FMC process. Based on the findings of the Ministry of Finance and monitoring in place, in some LGUs in the district of Gjirokastra, are observed positive aspects in the implementation phase of the system. Thus, there is knowledge of the new concepts and principles of FMC and an increase of awareness of CGU's from the moment of implementation (after 2010). It has begun the understanding of the importance of establishing sound systems of financial management and control. But it is noted a lack of awareness of the managers and staff, on the appropriate level, for managerial accountability which comes as a result of the low level of knowledge of FMC concepts in the Albanian reality.

It appears that some institutions still have not properly understood the concepts of FMC and managerial accountability. They have linked the completion of the questionnaire and reporting with the existence of proper control structures. This is reflected in many of the gaps and irregularities, such as:

- Lack of analysis, documentation and management of risks that hinder the achievement of the objectives of public entities.

- $\quad$ Lack of written rules and practices for the notification of irregularities.

- Lack of delegation of tasks at the appropriate level and regulation with normative acts.

- Management Control focuses mainly on financial aspects rather than on monitoring the objectives or efficiency. Reportings are mainly financial and do not include other information needed for management.

- There is a necessity for training the managers to use the information efficiently.

\footnotetext{
${ }^{1}$ The strategy of public finances $2014-2020$
} 
- The communication within the unit is not uniform and the staff is not always aware of the outcome of the proceedings to which they contribute.

These gaps and weaknesses are factors that adversely affect the implementation of the FMC system in achieving its goal of delivering a reasonable guarantee that the objectives of the organization are carried out with efficiency, economy and efficiency.

While the FMC system is implemented, the development is pregressing rapidly, thus it is required the construction of a model to provide continuity to pursue this reality that evolves very rapidly, it is required a new working culture, a professional standard more advanced and contemporary. Getting adjusted to this kind of continuous reform and movement is the main challenge of our institutions. These institutions must adapt to the rapid developments, the need for reform in the managerial culture in order to achieve the best European and international standards.

And part of this culture is to accept the challenge, the change and rapid adaptation to reality, with the most advanced model. This adaptation, in many cases requires sacrifices in some cases that are not easy to implement, because behind each reform there is the human and cultural factor. It is important to define what financial reform is needed and which should be its program to help the improvement of the internal control system, initially, in a situation when the management is weak and later when the management capacity is improved. This is the only way to ensure that Albanian citizens and taxpayers get the most out of their taxes and keep under continuous monitoring the performance of the institutions in general and their modernization.

\section{References}

[1] Bogdani, I., (2009) Public Accounting

[2] Decision of the Council of Ministers No. 640, dated 11.06.2009 "On approval of Policy papers for the public internal financial control and action plan of 2009-2014.

[3] IFAC (April 2004) "The Importance of Accrual-based Financial Reporting In the Public Sector".

[4] IFAC (March 2012) "The public sector and financial management transparency. Accountability, use of IPSAS"

[5] Law No. 10296 dated 08.07.2010 "On financial management and control"

[6] Law No. 9936 dated 26/06/2008 Budget Management System in RoA

[7] Manual for Financial Management and Control, agreed with the Minister of Finance Order No. 8980 dated 15/07/2010

[8] Ministry of Finance "Annual Report on the Functioning of Financial Management Systems and Control and Functioning of Internal Audit in the General Government entities for the period 1 January - 31 December, 2013," May 2014

[9] Ministry of Finance "Report on the Functioning of the Public Internal Financial Control in the General Government entities for 2014 Tirana" May 2015

[10] Ministry of Finance, Public Finance Strategy 2014-2020

[11] Ministry of Finance Public Finance Strategy 2007-2013

[12] Ministry of Finance (May 2015), "Report on the Functioning of the Public Internal Financial Control in the General Government entities for the year 2014 Tirana".

[13] Ministry of Finance (June 2011), "For the implementation of a modern system of FMC".5-year action plan. (20092014.

[14] "National audit on the national government service", Third scientific conference of high state control Tirana 2014

[15] Report no. 36,453. Albania Restructuring Public Expenditure to Sustain Growth "An Overview of Public Expenditure and Institutional framework" Volume II: Main Report December, 2006 Unit Poverty Reduction and Economic Management Europe and Central Asia Region Document Training materials "Governance and internal control" by the Central Entity for Harmonization of Financial Management and 